\title{
RETRACTED ARTICLE: Combining artificial neural network and unified particle swarm optimization for oil flow rate prediction: case study
}

Mohammad Ali Ahmadi · Seyed Reza Shadizadeh • Arash Goudarzi

Received: 13 November 2011/Accepted: 12 April 2012/Published online: 11 May 2012

(C) Springer-Verlag London Limited 2012

This article has been retracted at the request of the author, following concerns over the paper's integrity.

M. A. Ahmadi ( $\square)$

Department of Petroleum Engineering, Ahwaz Faculty of Petroleum Engineering, Petroleum University of Technology, P.O. BOX 63134, Ahvaz, Iran

e-mail: ahmadi6776@yahoo.com

S. R. Shadizadeh

Department of Petroleum Engineering, Abadan Faculty of Petroleum Engineering, Petroleum University of Technology,

Abadan, Iran

\section{A. Goudarzi}

Department of Petroleum Engineering,

Science and Research Branch,

Islamic Azad University, Tehran, Iran 